\title{
Trade (Dis)integration: The Sudden Death of NAFTA
}

\author{
Dimitrios Bakas $^{1,2}$ (D) Karen Jackson $^{3} \cdot$ Georgios Magkonis ${ }^{4}$
}

\begin{abstract}
This paper uses a structural PVAR model to study the macroeconomic effects of trade disintegration among NAFTA members. The results reveal substantial asymmetric responses, showing that the US is the most affected economy from a sudden negative trade integration shock. Moreover, Canada and the US are found to be relatively more interconnected with each other compared to the Mexican economy. Our findings question the US decision to push for the renegotiation of the NAFTA agreement.
\end{abstract}

Keywords NAFTA · Trade integration · Panel VAR

JEL Classification F14 $\cdot$ F15 $\cdot$ C33

\section{Introduction}

Regionalism has entered a new phase, with mega-regional trade negotiations suddenly collapsing and unexpected withdrawals from long-standing integration schemes. Deep divisions and turmoil over trade issues have been epitomised in the uncertain future of the North American Free Trade Area (NAFTA), where President Trump recently called for a renegotiation of the deal. This environment has led to questions about the effects of a 'break-up' shock. There are a number of notable examples, in the regionalism

Electronic supplementary material The online version of this article (https://doi.org/10.1007/s11079-01909567-1) contains supplementary material, which is available to authorized users.

Dimitrios Bakas

dimitrios.bakas@ntu.ac.uk

1 Nottingham Business School, Nottingham Trent University, Nottingham, UK

2 Rimini Centre for Economic Analysis (RCEA), Waterloo, Canada

3 Westminster Business School, University of Westminster, London, UK

4 Portsmouth Business School, University of Portsmouth, Portsmouth, UK 
literature, on the collapse of large-scale and/or long-standing integration schemes: the break-up of empires (Head et al. 2010), the soviet block (Fidrmuc and Fidrmuc 2003) and more recently, Brexit (Dhingra et al. 2017). Head et al. (2010) explore the trade dynamics of former colonies with their coloniser, within a gravity framework. They find that hostile seperations, conceptually not too far removed from to a break-up shock, have a stronger immediate negative impact on trade compared to a mutually accepted split. While methodologically similar, Fidrmuc and Fidrmuc (2003) examine the trade effects of the collapse of the Soviet block and find evidence of a strong decrease of home bias in trade relations; where Suesse (2018) utilise a game-theoretical model and argue that even the expectation of the Soviet block collapse was sufficient to create a strong negative effect on trade that impacted on output. However, Thom and Walsh (2002) find no evidence of a negative impact of the break-up of the union, measured by the introduction of an exchange rate between the UK and Ireland in 1979. Finally, the recent evidence of Dhingra et al. (2017) on the welfare effects of Brexit, using a computational general equilibrium model, shows that the UK welfare losses from higher trade barriers will exceed fiscal savings. In summary, the literature exploring disintegration is limited and has yielded mixed results. Therefore, much less is known about the effect of negative integration shocks compared to trade integration (Manchester and McKibbin 1995). Furthermore, the methodologoical approaches used in the aforementioned studies are not intented to specifically explore the impact of an unexpected shock. Hence, the novelty of this paper is that it focuses on the impact of a surprise disintegration on the macro-fundamentals of NAFTA countries.

Methodologically, the analysis of unexpected shocks or surprises is typically undertaken within a structural vector autoregression (SVAR) modelling framework. This type of analysis is frequently applied, and the advantages are well understood, in the context of business cycles and the monetary transmission mechanism (Fève et al. 2018). On the other hand, research using SVAR modelling to consider the impact of shocks in a trade setting is still in its infancy. For example, Çakir and Kabundi (2013) investigate an export/import shock, Nordmeier et al. (2016) a trade liberalization shock, Du et al. (2017) a political relations shock, and, most recently, Schmitt-Grohé and Uribe (2018) consider a terms of trade shock. Schmitt-Grohé and Uribe (2018) focus on a group of emerging and poor countries and find that terms of trade shocks have a more limited impact on key macroeconomic indicators, than one would expect based on the findings from models with micro-foundations. The focus for Nordmeier et al. (2016) is somewhat different, where they explore the impact of a trade liberalisation shock on the German labour market; they find a positive effect broadly in line with the existing literature. Du et al. (2017) find that political shocks die out quickly, and therefore highfrequency data is required to identify the impact of such shocks on trade. The authors also find that gravity models use low frequency data, and in doing so fail to identify the impact of these shocks. Finally, Çakir and Kabundi's (2013) global VAR (GVAR) analysis allows the authors to identify trade linkages between South Africa and the BRIC (Brazil, Russia, India and China) countries. Therefore, this paper contributes to this emerging literature by exploring the impact of a trade disintegration shock.

Furthermore, in comparison to the current literature, we explore a trade disintegration shock within a structural panel VAR (PVAR) framework; thereby allowing us to examine the effect of the shock on various macroeconomic indicators for the three members of NAFTA (Canada, Mexico and the US). The main advantage of PVARs 
over traditional SVAR models is the addition of the cross-sectional structure. More precisely, the PVAR model can account for cross-sectional heterogeneities as well as for static and dynamic interdependencies in a multi-country framework (Montiel and Pedroni 2019). In the next section, we properly analyse these properties. In this way, PVARs can capture greater variety of potential interlinkages than GVARs (Pesaran et al. 2004), which impose a particular structure on the interdependencies. These are significant properties that allows us to assess and test the potential linkages and spillovers among the examined economies. In conducting this analysis, we provide a timely contribution to the literature considering the potential impact of a sudden collapse of trade between NAFTA members. Furthermore, we illustrate the usefulness of PVAR modelling to explore the responses to a trade disintegration shock for the NAFTA participants.

Our empirical results show a significant degree of heterogeneity in terms of macroeconomic responses of the three NAFTA members, and reveal that the US economy is the most vulnerable to a negative trade integration shock. Furthermore, the US and Canadian economies are found to be more interlinked with each other as opposed to Mexico. These findings question the decision by the US administration for a renegotiation or full withdrawal from the NAFTA agreement.

The rest of the paper is organized as follows. Section 2 presents the empirical model and the data. Section 3 discusses the empirical results and provides the robustness checks. Finally, Section 4 concludes.

\section{Empirical Model and Data}

\subsection{Model}

Our model is built upon a panel vector autoregressive (PVAR) framework, where the terminology that we use thereafter is based on Canova and Ciccarelli (2013). In general, PVAR models are increasingly becoming a popular tool for examining the interactions of several entities (see for example Apostolakis and Papadopoulos 2019; Montiel and Pedroni 2019). The main advantage over traditional structural VARs is the addition of a cross-sectional structure. This is a significant property that allows us to assess and test the potential linkages and spillovers among the examined countries. Letting $y_{i, t}$ be a vector of $G$ endogenous variables of country $i(i=1, \ldots, N)$ at time $t(t=1, \ldots, T)$ with $l$ lags $(l=1, \ldots, L)$ and $x_{t}$ a set of $M$ exogenous variables, common to all units, the PVAR model is written as:

$$
\begin{aligned}
y_{i, t}= & A_{i 1, t}^{1} y_{1, t-1}+\ldots+A_{i 1, t}^{L} y_{1, t-L}+A_{i 2, t}^{1} y_{2, t-1}+\ldots+A_{i 2, t}^{L} y_{2, t-L}+\ldots+A_{i N, t}^{1} y_{N, t-1} \\
& +\ldots+A_{i N, t}^{L} y_{N, t-L}+C_{i, t} x_{t}+e_{i, t}
\end{aligned}
$$

where $A_{i j, t}^{l}$ are $G^{*} G$ matrices, $C_{i, t}$ is a $G^{*} M$ matrix and $e_{i, t}$ are the uncorrelated over-time errors distributed as $N\left(0, \Sigma_{i i, t}\right)$ with $\Sigma_{i i, t}$ the variance-covariance matrix. The model can be re-written in analytical form as: 


$$
\begin{aligned}
\left(\begin{array}{c}
y_{1, t} \\
y_{2, t} \\
\vdots \\
y_{N, t}
\end{array}\right)= & \left(\begin{array}{cccc}
A_{11, t}^{1} & A_{12, t}^{1} & \cdots & A_{1 N, t}^{1} \\
A_{21, t}^{1} & A_{22, t}^{1} & \cdots & A_{2 N, t}^{1} \\
\vdots & \vdots & \ddots & \vdots \\
A_{N 1, t}^{1} & A_{N 2, t}^{1} & \cdots & A_{N N, t}^{1}
\end{array}\right)\left(\begin{array}{c}
y_{1, t-1} \\
y_{2, t-1} \\
\vdots \\
y_{N, t-1}
\end{array}\right)+\ldots \\
& +\left(\begin{array}{cccc}
A_{11, t}^{L} & A_{12, t}^{L} & \cdots & A_{1 N, t}^{L} \\
A_{21, t}^{L} & A_{22, t}^{L} & \cdots & A_{2 N, t}^{L} \\
\vdots & \vdots & \ddots & \vdots \\
A_{N 1, t}^{L} & A_{N 2, t}^{L} & \cdots & A_{N N, t}^{L}
\end{array}\right)\left(\begin{array}{c}
y_{1, t-L} \\
y_{2, t-L} \\
\vdots \\
y_{N, t-L}
\end{array}\right)+\left(\begin{array}{c}
C_{1, t} \\
C_{2, t} \\
\vdots \\
C_{N, t}
\end{array}\right) x_{t}+\left(\begin{array}{c}
e_{1, t} \\
e_{2, t} \\
\vdots \\
e_{N, t}
\end{array}\right),
\end{aligned}
$$

$$
\text { with } e_{i, t} \sim N\left(0, \Sigma_{i i, t}\right) \text { and } \Sigma_{i i, t}=\left(\begin{array}{cccc}
\Sigma_{11, t} & \Sigma_{12, t} & \cdots & \Sigma_{1 N, t} \\
\Sigma_{21, t} & \Sigma_{22, t} & \cdots & \Sigma_{2 N, t} \\
\vdots & \vdots & \ddots & \vdots \\
\Sigma_{N 1, t} & \Sigma_{N 2, t} & \cdots & \Sigma_{N N, t}
\end{array}\right) \text {, }
$$

where $y_{i, t}$ is the vector of endogenous variables, $x_{t}$ contains the exogenous variables and $e_{i, t}$ are the error terms.

The unrestricted PVAR specification suffers from over-parameterization; this is because even a small PVAR is characterised by high parameter-space dimensionality. ${ }^{1}$ Overcoming this problem requires the imposition of structural restrictions. We focus on four groups of restrictions; (i) cross-sectional heterogeneities, (ii) dynamic interdependencies, (iii) static interdependencies and (iv) dynamic heterogeneities. In the present context, it would be unrealistic to assume the homogeneity of the examined economies. Therefore, we allow for cross-sectional heterogeneities, i.e., $A_{i k, t}^{l} \neq A_{j k, t}^{l}$ and $\Sigma_{i i, t} \neq \Sigma_{j j, t}$ when $i \neq j$. In addition, since we are interested in capturing all the potential cross-sectional linkages among the examined economies, we assume that our system is characterised by dynamic interdependencies. Thus, the endogenous variables of each country depend on the lags of the endogenous variables of every other country. Using the above notation, this is equivalent to $A_{i j, t}^{l}$ $\neq 0$ when $i \neq j$. Furthermore, given the close economic ties among NAFTA members, we also allow for static interdependencies. Mathematically, $\Sigma_{i j, t} \neq 0$ when $i \neq j$. Therefore, we let a shock in one country be transmitted to another country. Finally, given the relative short time-span, it seems reasonable to assume dynamic homogeneity (homoscedasticity). These are the type of restrictions that we impose in our model, i.e., $A_{i j, t}^{l}=A_{i j, s}^{l}$ and $\Sigma_{i j, t}=\Sigma_{i j, s}$, when $t \neq s$. The advantage of our PVAR specification is that allows for dynamic interactions among economies. In this way, our model differs from single VARs that are estimated using either data from one country or panel data (pooled estimates). The details of our estimation strategy are described in the online Appendix.

\footnotetext{
${ }^{1}$ In the unrestricted version of our relatively small PVAR, with $G=4, N=3, M=1$ and $L=1,225$ model parameters and 120 error variances and covariances should be estimated.
} 


\subsection{Data}

We use annual data for the period 1950-2011 for the three members of the NAFTA trade bloc (Canada, Mexico and the US). ${ }^{2}$ The endogenous variables used in the analysis consist of: i) historical trade integration index (HTI), ii) real GDP (GDP), iii) consumption (CON) and iv) investment (INV). As an exogenous variable we use the spot crude oil price (OIL) as a proxy for supply side effects. The selection of macroeconomic variables, which are all expressed as log-deviations from the trend, is based on the work of Schmitt-Grohé and Uribe (2018) and are collected from the IMF-IFS database, while the oil price is from the FRED database. The HTI index is based on the work of Standaert et al. (2016). ${ }^{3}$ The index is based on a state-space model that combines four alternative indicators of the level of trade integration into one overall index. The main advantage of this index is its bilateral nature, where $\mathrm{HTI}_{i \rightarrow j}$ identifies country $i$ as the exporter to country $j$, where $\mathrm{HTI}_{i \rightarrow j} \neq \mathrm{HTI}_{j \rightarrow i}$. In this way, we have six different subindexes; HTI ${ }_{C A N \rightarrow M E X}, \mathrm{HTI}_{M E X \rightarrow C A N}$, HTI $U S \rightarrow C A N, \mathrm{HTI}_{C A N \rightarrow U S}$, HTI $U S \rightarrow M E X$ and HTI $M E X \rightarrow U S$. Each of these indexes proxies the level of trade integration between the two countries (Standaert et al. 2016). For instance, HTI $C A N \rightarrow M E X$ refers to bilateral trade integration between Canada and Mexico from the Canadian perspective, i.e., an increase in the HTI $C A N \rightarrow M E X$ indicates that Canadian-Mexican trade is becoming more important from the Canadian point of view. In this particular case, our results will show the response of the Canadian macroeconomic variables to a shock in HTI CAN $\rightarrow$ MEX. Figure 1 shows the evolution of the bilateral HTI indexes for the NAFTA members over the period 1950-2011. The figure shows evidence of considerable heterogeneity in the trade integration across the NAFTA participants.

\section{Empirical Results}

\subsection{Main Results}

We start the exposition of our results with reference to the GDP impulse responses presented in Fig. 2. All shocks represent a 1\% decrease in the HTI integration index (which we name as a disintegration shock). The left panel on the first row of Fig. 2 plots the Canadian GDP response to a negative shock in HTI $C A N \rightarrow U S$. The right panel on the first row presents the Canadian GDP response to a shock in HTI $C A N \rightarrow M E X$. In a similar vein, the second row shows the Mexican GDP response to a shock in $\mathrm{HTI}_{M E X \rightarrow}$ $C_{C A N}$ (left panel) and a shock in HTI $M E X \rightarrow U S$ (right panel). Finally, the third row shows the US response from shocks in HTI $U S \rightarrow C A N$ and HTI $U S \rightarrow M E X$, respectively.

Findings from the left panel in Fig. 2 suggest that Canadian and US activity is negatively affected, with the US experiencing the highest and the longest impact. Interestingly, our evidence suggests that both economies respond negatively on impact. This reflects the strong interconnection between the two economies. On the contrary, a

\footnotetext{
${ }^{2}$ The year 2011 is the last available observation of the HTI index.

${ }^{3}$ We follow the approach of Sims et al. (1990), Lin and Tsay (1996) and Choi (2017), according to which it is still desirable to estimate a VAR model, even if the variables contain unit roots.
} 

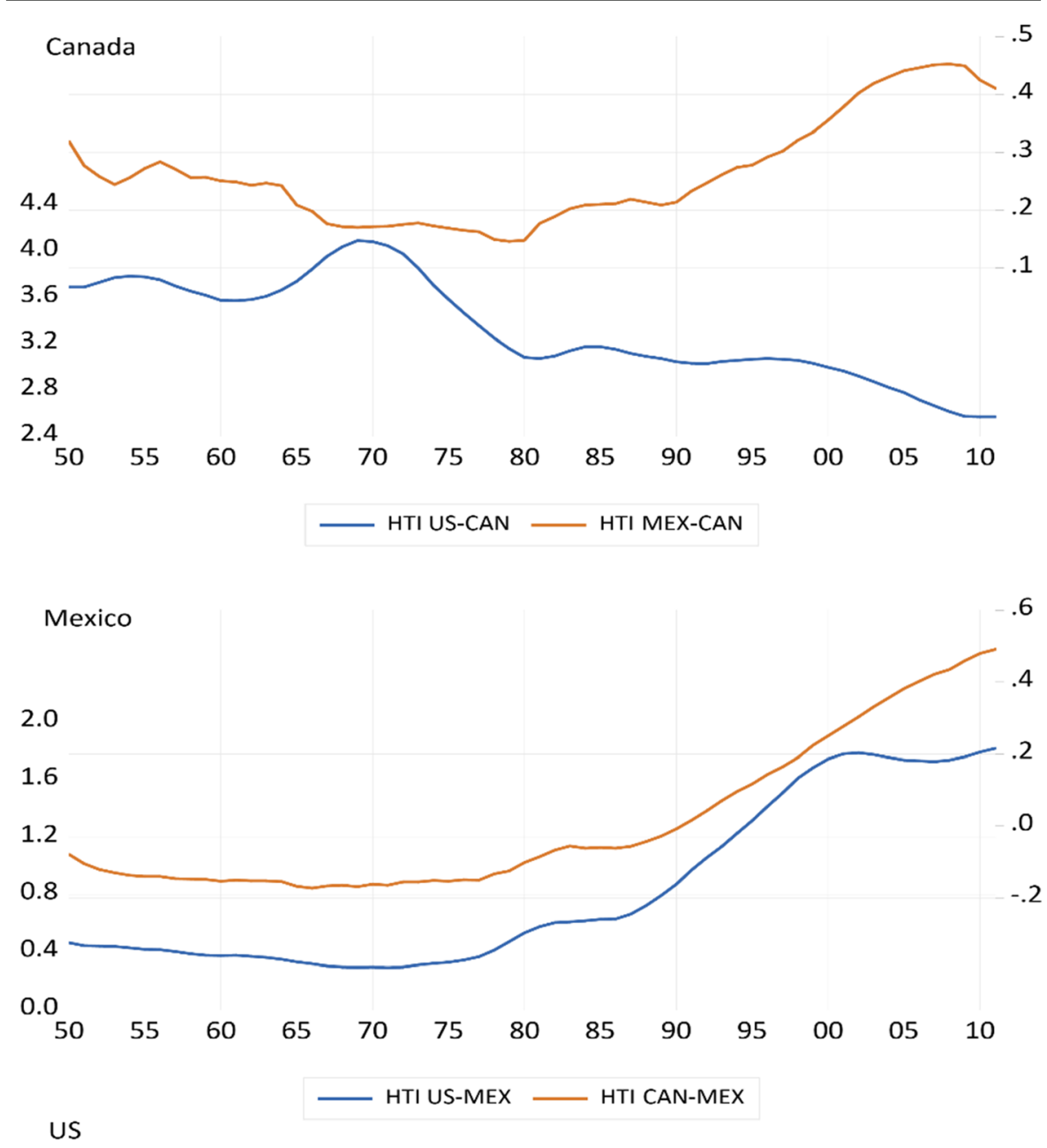

13.5

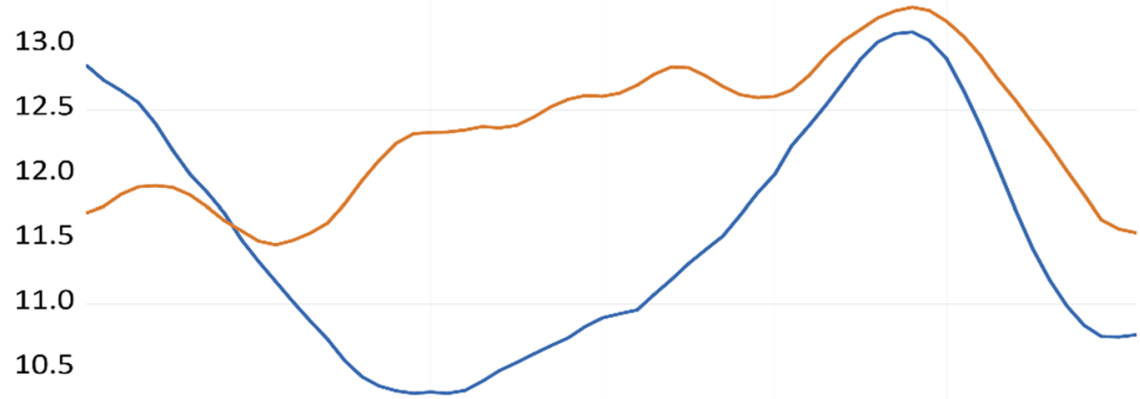

10.0

$$
\begin{aligned}
& \begin{array}{lllllllllllll}
50 & 55 & 60 & 65 & 70 & 75 & 80 & 85 & 90 & 95 & 00 & 05 & 10
\end{array} \\
& \text { HTI MEX-US } \\
& \text { HTI CAN-US }
\end{aligned}
$$

Fig. 1 The bilateral trade integration index (HTI) for the three NAFTA members (1950-2011) 

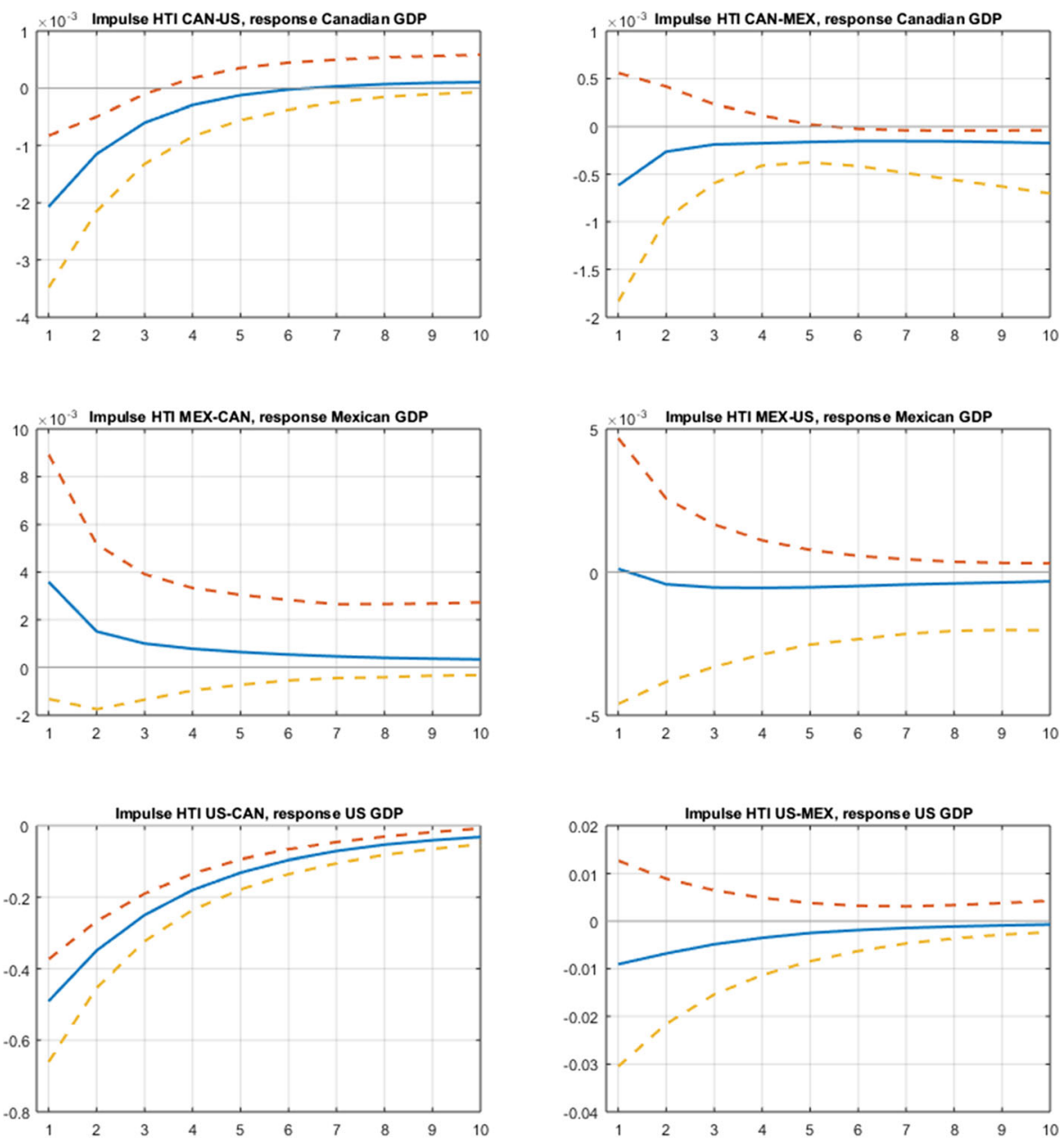

Fig. 2 Impulse responses of the Canadian, Mexican and US real GDP (GDP) to a negative shock to the bilateral trade integration index (HTI)

shock in HTI $C A N \rightarrow M E X$ and HTI $U S \rightarrow M E X$ does not impact economic activity in Canada and the US in a statistically significant way. As far as Mexican economic activity is concerned (second row of Fig. 2), our evidence reveals that Mexico is robust to a trade disintegration shock; both GDP responses are statistically insignificant. One possible explanation is that Mexican exports could still be traded with US/Canada outside the NAFTA agreement, particularly those that support supply chains, or to alternative markets without significant increases in economic costs. ${ }^{4}$

Figures 3, 4 and 5 show the impulse responses of the remaining macroeconomic variables (CON and INV) for the three NAFTA members. The left panel of Fig. 3 plots the responses of Canadian consumption and investment to a negative shock in HTI $C A N \rightarrow U S$. The effects in both variables are negative and statistically significant.

\footnotetext{
${ }^{4}$ Recent evidence suggests that the benefits to Mexico from the NAFTA deal are limited (Ramírez Sánchez et al. 2018).
} 
Investment initially decreases by $0.02 \%$, while consumption is reduced by slightly less. Even though the reduction is not large, the variables return to their pre-shock levels only after 4 years. The right panel of Fig. 3 shows the effect for the Canadian economy of a negative shock to HTI $C A N \rightarrow M E X$. Our evidence suggests that the Canadian economy responds negatively on impact. However, the effects are both economically and statistically insignificant. This asymmetric reaction of Canada reflects the primary role of the US economy.

Looking into the Mexican economy, the reaction to HTI shocks presents quite an interesting outcome. For the former case (the integration between Mexico and Canada), the left panel of Fig. 4 shows that Mexican consumption and investment increase as result of a negative shock. However, this increase is statistically insignificant as the broad error bands depict. For the case of a HTI $M E X \rightarrow U S$ shock (right panel of Fig. 4), the reaction is roughly zero.

Turning to the US economy, our evidence reveals further asymmetries. A sudden negative shock to HTI $U S \rightarrow C A N$ has a significant economic cost for the US, as it is depicted in the left panel of Fig. 5. A $1 \%$ decrease in HTI causes a roughly $0.5 \%$ reduction in both consumption and investment. On the other hand, the US seems to be unaffected by a negative shock in HTI $U S \rightarrow M E X$. The responses presented in the right panel of Fig. 5 show negative albeit insignificant reactions.

In addition, we supplement our main empirical results with a battery of tests, using alternative specifications, orderings and transformations of the variables in the structural PVAR model, to check the robustness of our findings. As a first exercise, we estimate the implulse responses based on the PVAR model without the inclusion of the
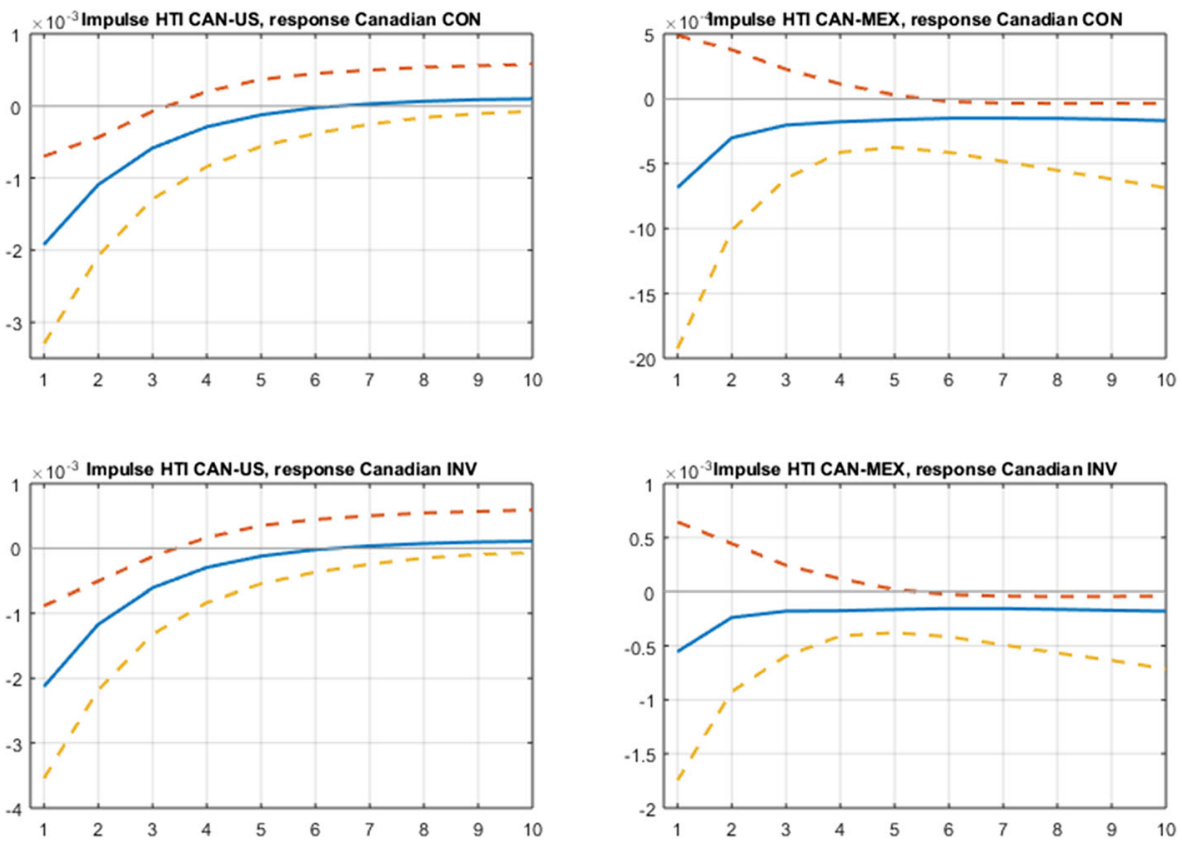

Fig. 3 Impulse responses of the Canadian consumption (CON) and investment (INV) to a negative shock to the bilateral trade integration index (HTI) between Canada-US and Canada-Mexico 

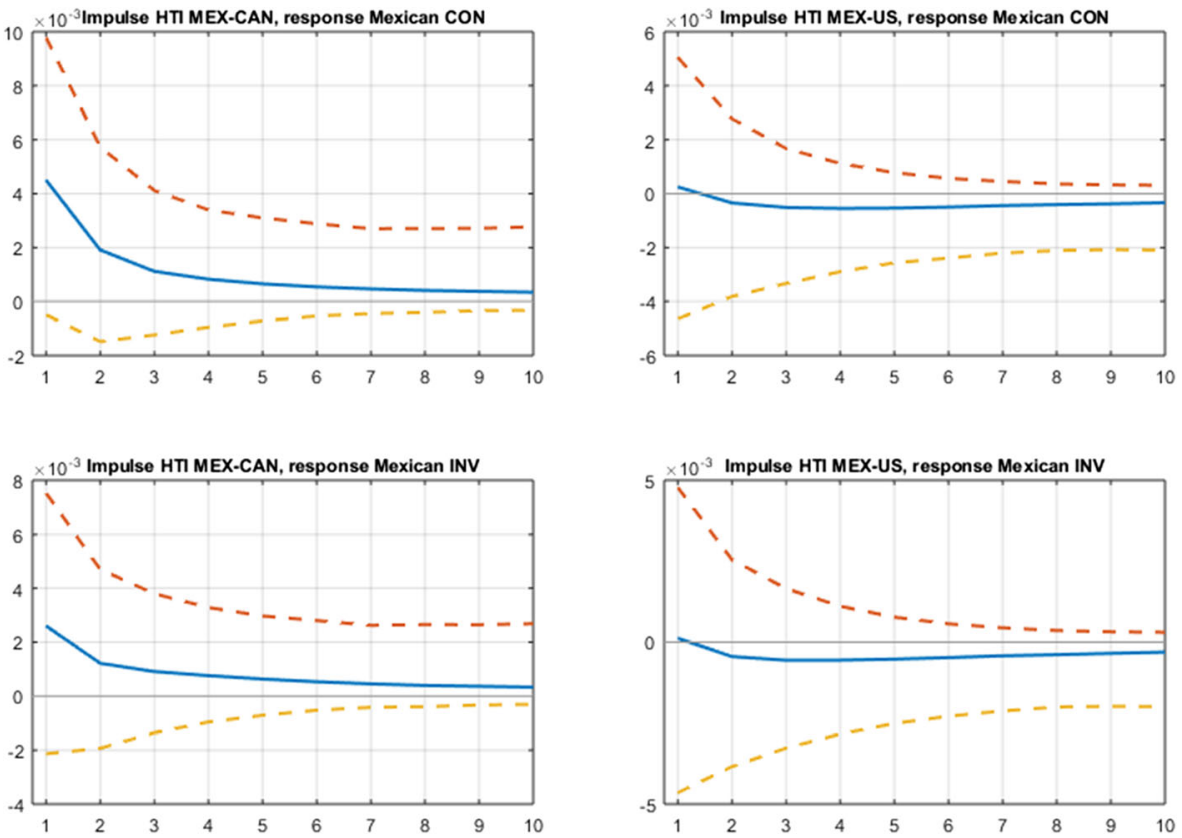

Fig. 4 Impulse responses of the Mexican consumption (CON) and investment (INV) to a negative shock to the bilateral trade integration index (HTI) between Mexico-Canada and Mexico-US

exogenous variable (OIL) in our specification. Our results and main conclusions remain almost identical. Additionally, we employ the PVAR model using alternative orderings
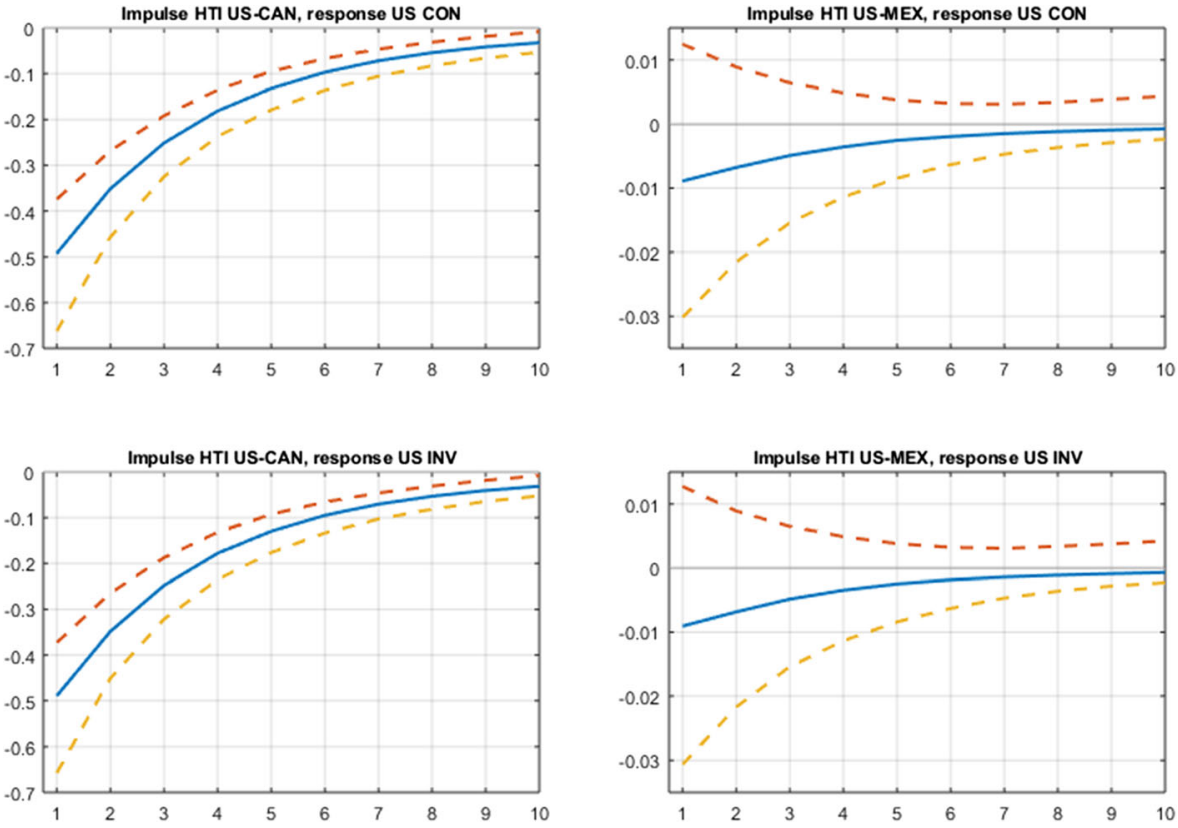

Fig. 5 Impulse responses of the US consumption (CON) and investment (INV) to a negative shock to the bilateral trade integration index (HTI) between US-Canada and US-Mexico 
of the endogenous variables and we find that the results remain robust. Lastly, we replicate the PVAR analysis using the logs of the endogenous variables (without using the series transformed in log-deviations from the trend) and our main results remain unaltered. $^{5}$

Overall, our PVAR model reveals strong evidence of asymmetries among the three NAFTA members. The economy more susceptible to trade disintegration is found to be the US and, then, Canada. On the contrary, Mexico proves to be quite robust to a sudden trade shock. Moreover, the US and Canadian economies are found to be relatively more interconnected with each other rather than with the Mexican economy. Our results reaffirm the recent evidence of Weisbrot et al. (2014) and Ramírez Sánchez et al. (2018), while we call into question the earlier findings on the effects of NAFTA by Krueger (1999) and Burfisher et al. (2001).

\subsection{Robustness}

To examine further the robustness of our main results, we consider a second PVAR model where we use an alternative measure of trade integration and we implement higher frequency (quarterly) data. In this PVAR model we follow the same structure with our main PVAR but we replace the $\mathrm{HTI}_{i \rightarrow j}$ index with an alternative measure; that is, export share: XS ${ }_{i \rightarrow j}$. More precisely, we replace the HTI $M E X \rightarrow U S$ with $\mathrm{XS}_{M E X \rightarrow U S}$. In this particular example, $\mathrm{XS}_{M E X \rightarrow U S}=\left(\left(\mathrm{X}_{M E X \rightarrow U S} / \mathrm{X}_{M E X \rightarrow W O R L D}\right) \times\right.$ 100 ), where $\mathrm{X}_{i \rightarrow j}$ represents the exports of country $i$ to $j$. Given the quarterly frequency of the new dataset, we split the sample into two subperiods; 1969Q11993Q4 and 1994Q1-2018Q4 covering the pre-NAFTA and post-NAFTA periods, respectively. The data for the export shares are collected from the WITS database of the World Bank, while the rest of the variables are from the IMF-IFS database. To facilitate the readibility of the results, we present the impulse responses of GDP to a $1 \%$ negative shock in the $\mathrm{XS}{ }_{i \rightarrow j}$ measure. The remaining impulse responses (CON and INV) are presented in the online Appendix.

Figure 6 presents the GDP impulse responses for the three economies for the preNAFTA period, while Fig. 7 shows the corresponding results for the post-NAFTA period. Following the same structure of Fig. 2, the first row shows the Canadian responses, the second row presents the Mexican ones, while the last row shows the US responses. All GDP impulse responses for the pre-NAFTA period are statistically insignificant. The only exception is the US response to a XS $U S \rightarrow C A N$ shock. On the contrary, the results are different when we examine the post-NAFTA period. While Mexican GDP responses are found insignificant, both the Canadian and the US GDP are reduced after a negative shock in XS $C A N \rightarrow U S$ and XS $U S \rightarrow C A N$, respectively. Interestingly, the US GDP reduction remains larger than the Canadian one.

Once more, the evidence suggests the asymmetry across the three economies highlighting the stronger interconnections between Canada and US. The pattern of responses for consumption and investment for the post-NAFTA period is quantitatively and qualitatively the same with the main results (available in the online Appendix).

\footnotetext{
$\overline{5}$ These results can be provided upon request.
} 

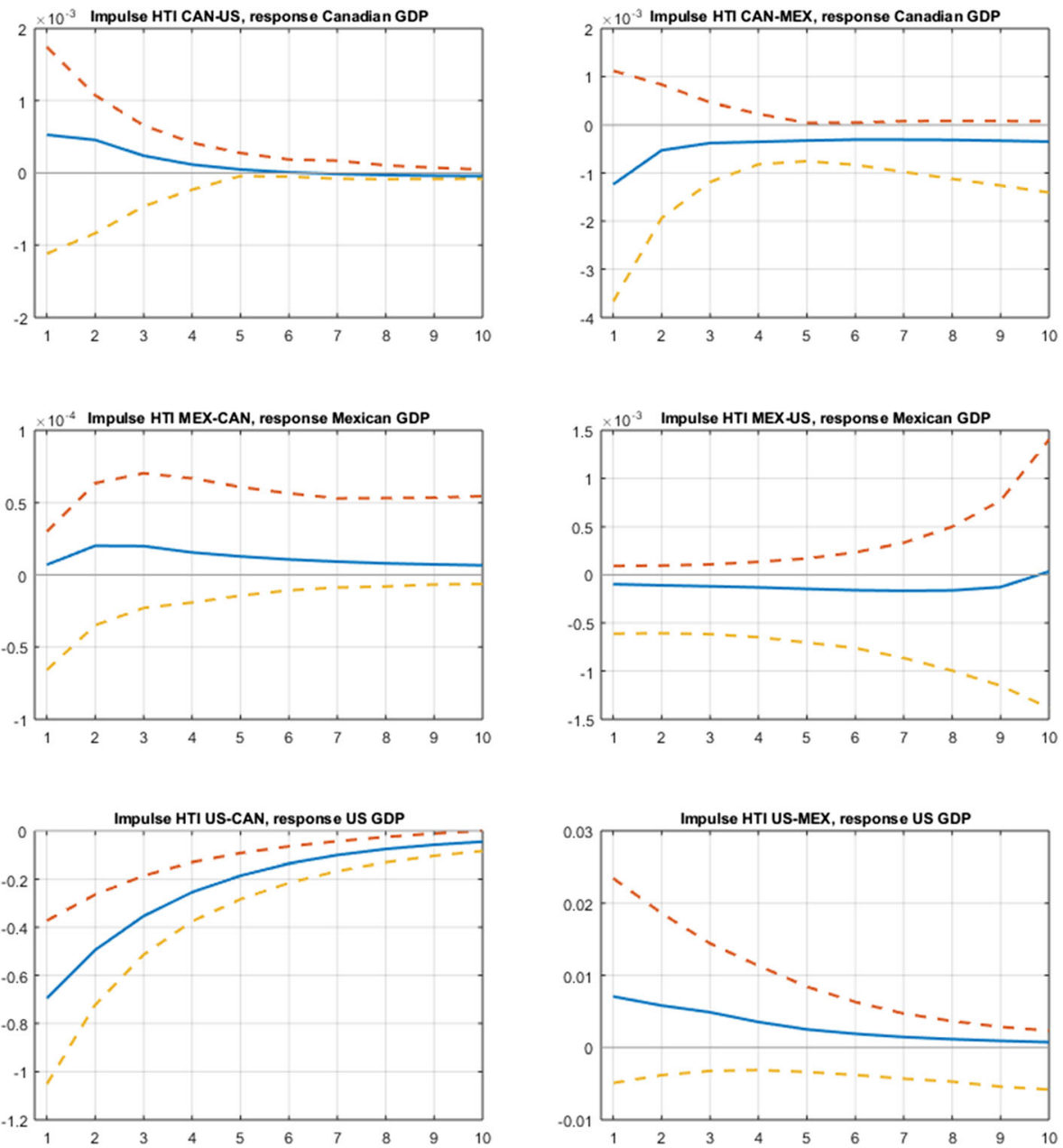

Fig. 6 Impulse responses of the Canadian, Mexican and US real GDP (GDP) to a negative shock to the export share measure $(\mathrm{XS})$ for the pre-NAFTA period

\section{Conclusions}

The present paper is the first study that explores trade disintegration shocks within a structural PVAR framework. The current interest in the NAFTA integration scheme, and its potential disintegration in particular, provides an ideal setting to illustrate the usefulness of this methodology. The PVAR framework allows us to assess and test the potential linkages and spillovers among the NAFTA economies when faced with an unexpected shock. Moreover, the recent trend of sudden trade disintegration shocks, provides a number of other settings where this methodology could be applied in future.

By taking into account cross-country heterogeneity, we are able to identify asymmetric macroeconomic responses to trade disintegration among the three NAFTA participants. The US is found to have the highest losses, while Mexico the least. Canada has already started to diversify its export markets by signing new trade deals 

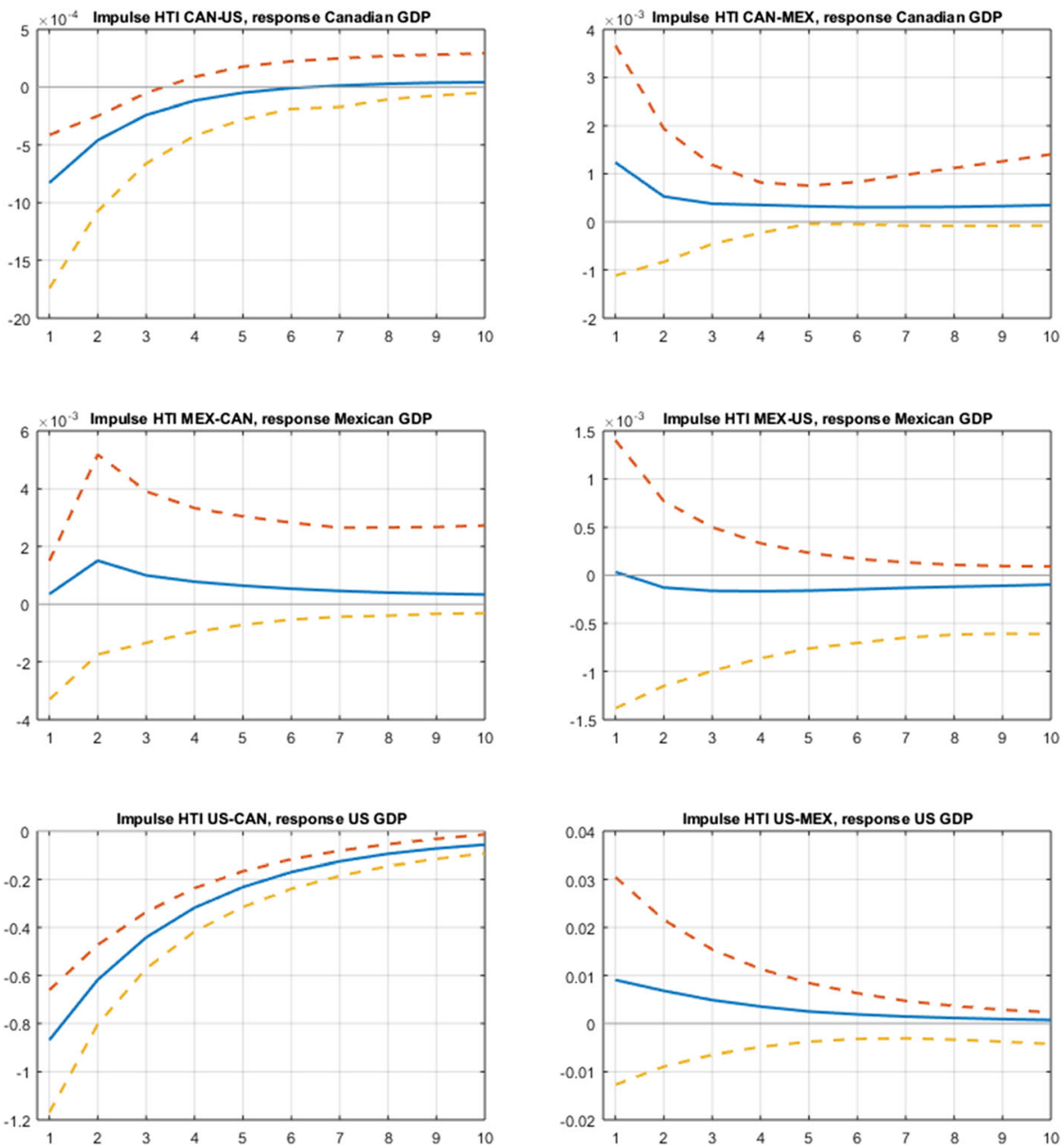

Fig. 7 Impulse responses of the Canadian, Mexican and US real GDP (GDP) to a negative shock to the export share measure (XS) for the post-NAFTA period

(for example, the Comprehensive Economic and Trade Agreement (CETA) with the European Union and the Trans-Pacific Partnership (TPP) with the Pacific Rim countries), which are likely to further mitigate the negative effects of a potential collapse of NAFTA. In terms of Mexico, they would experience non-tariff barrier reductions (for example, by avoiding the NAFTA Rules of Origin) by trading under World Trade Organisation rules, which would go some way to mitigate the associated tariff increases. On the other hand, US consumers would experience higher prices due to increases in trade costs, where there is also the potential for additional US welfare loss due to any retaliation from Mexico and Canada. Overall, our findings suggest that a sudden unexpected negative shock on the integration of the NAFTA block damages the US. 
Acknowledgments We would like to thank the Editor, George S. Tavlas and two anonymous referees for their constructive comments and helpful suggestions. In addition, we would like to thank the participants of the 20th European Trade Study Group Conference 2018 (ETSG 2018) for their comments and suggestions. Any remaining errors are the responsibility of the authors. The authors declare that they have no conflict of interest.

Open Access This article is distributed under the terms of the Creative Commons Attribution 4.0 International License (http://creativecommons.org/licenses/by/4.0/), which permits unrestricted use, distribution, and reproduction in any medium, provided you give appropriate credit to the original author(s) and the source, provide a link to the Creative Commons license, and indicate if changes were made.

\section{References}

Apostolakis G, Papadopoulos AP (2019) Financial stability, monetary stability and growth: a PVAR analysis. Open Econ Rev 30:157-178

Burfisher ME, Robinson S, Thierfelder K (2001) The impact of NAFTA on the United States. J Econ Perspect 15:125-144

Çakir MY, Kabundi A (2013) Trade Shocks from BRIC to South Africa: a global VAR analysis. Econ Model 32:190-202

Canova F, Ciccarelli M (2013) Panel vector autoregressive models: a survey. In: VAR models in macroeconomics-new developments and applications: essays in honor of Christopher A. Sims. Emerald, Bingley, pp 205-246

Choi. S. (2017). Variability in the effects of uncertaintt shocks: New stylized facts from OECD countries, Journal of Macroeconomics, 53, 127-144.

Dhingra S, Huang H, Ottaviano G, Paulo Pessoa J, Sampson T, Van Reenen J (2017) The costs and benefits of leaving the EU: trade effects. Econ Policy 32:651-705

Du Y, Ju J, Ramirez CD, Yao X (2017) Bilateral trade and shocks in political relations: evidence from China and some of its major trading partners, 1990-2013. J Int Econ 108:211-225

Fève P, Garcia P, Sahuc JG (2018) State-dependent risk taking and the transmission of monetary policy shocks. Econ Lett 164:10-14

Fidrmuc J, Fidrmuc J (2003) Disintegration and trade. Rev Int Econ 11:811-829

Head K, Mayer T, Ries J (2010) The Erosion of colonial trade linkages after Independence. J Int Econ 81:1-14

Krueger AO (1999) Trade creation and trade diversion under NAFTA, Working paper 7429, National Bureau of Economic Research

Lin, J.L., and Tsay, R.S. (1996). Co-integration constraint and forecasting: an empirical examination. Journal of Applied Econometrics, 11, 519-538.

Manchester J, McKibbin WJ (1995) The global macroeconomics of NAFTA. Open Econ Rev 6:203-223

Montiel PJ, Pedroni P (2019) Trilemma-dilemma: constraint or choice? Some empirical evidence from a structurally identified heterogeneous panel VAR. Open Econ Rev 30:1-18

Nordmeier D, Schmerer HJ, Weber E (2016) Trade and labor market dynamics: what do we learn from the data? Econ Lett 145:206-209

Pesaran MH, Schuermann T, Weiner SM (2004) Modeling regional interdependencies using a global errorcorrecting macroeconometric model. J Bus Econ Stat 22:129-162

Ramírez Sánchez JC, Calderón C, León SS (2018) Is NAFTA really advantageous for Mexico? Int Trade J 32: 21-42

Schmitt-Grohé S, Uribe M (2018) How important are terms-of-trade shocks? Int Econ Rev 59:85-111

Sims, C.A., Stock, J.H., and Watson, M.W. (1990). Inference in linear time series models with some unit roots. Econometrica, 58, 113-144.

Standaert S, Ronsse S, Vandermarliere B (2016) Historical trade integration: globalization and the distance puzzle in the long twentieth century. Cliometrica 10:225-250

Suesse M (2018) Breaking the unbreakable union: nationalism, disintegration and the Soviet economic collapse. Econ J 128:2933-2967

Thom R, Walsh B (2002) The effect of a currency union on trade: lessons from the Irish experience. Eur Econ Rev 46:1111-1123

Weisbrot M, Lefebvre S, Sammut J (2014) Did NAFTA help Mexico? An assessment after 20 years, Report no. 2014-03, Center for Economic and Policy Research

Publisher's Note Springer Nature remains neutral with regard to jurisdictional claims in published maps and institutional affiliations. 